\title{
Variação linguística em livro didático do ensino fundamental: propostas e tratamento
}

\section{Linguistic Variation in Textbook of Middle School: Proposals and Treatment}

Aluiza Alves de Araújo1, Maria Lidiane de Sousa Pereira²

Doutora e mestre em Linguística pela Universidade Federal do Ceará (UFC). Graduada em Letras pela Universidade Estadual do Ceara (UECE). curso de Pós-Graduãão em Linguística Aplicada (PosLA) do Centro de Humanidades (CH) da UECE. Atua na área de Letras com ênfase em Linguística, Sociolinguística e Dialetologia. É coordenadora do projeto Retratos sociolinguisticos de aspectos fonologicos, mortogicos e sintalicos do falar de E-mail: aluizazinh

Doutoranda e mestre em Linguística Aplicada pelo Programa de Pós-Graduação em Linguística Aplicada (PosLA) do Centro de Humanidades (CH) da Universidade Estadual do Ceará (UECE). Graduada em Letras pela Universidade Regional do Cariri (URCA). Atua na area de Letras com Portuguesa. Atualmente é bolsista de doutorado pela Coordenação de Aperfeiçoamento de Pessoa de Nivel Superior (CAPES)

E-mail: lidiane_lidiarock@hotmail.com
RESUMO: Neste artigo, objetivamos discutir algumas das propostas para o trabalho com a variação linguística no ensino formal de língua materna e analisar como esse fenômeno é abordado no livro didático Vontade de saber português (ALVES; BRUGNEROTTO, 2012), mais precisamente no volume direcionado aos alunos do 6ㅇa ano do ensino fundamental da rede pública. Para tanto, observamos algumas das propostas para o estudo da variação linguística fornecidas pelos PCN (BRASIL, 1998) e pelo PNLD (BRASIL, 2014) colocando-as em paralelo com o tratamento do fenômeno de variação linguística no livro analisado. Com base nas análises realizadas, percebemos que, embora tenhamos avançado significativamente quanto à elaboração de propostas para o trabalho com a variação linguística em materiais didáticos e, consequentemente, em sala de aula, ainda é possível encontrar algumas lacunas e até inadequações no modo como a variação linguística é trabalhada por tais materiais. Assim, compreendemos que a abordagem de um dos mecanismos mais importantes das línguas naturais fica comprometida.

PALAVRAS-CHAVE: Propostas; Variação Linguística; Livro Didático.

ABSTRACT: In this article, we aim to discuss some of the proposals to work with the linguistic variation in the formal schooling of mother tongue, and analyze how this phenomenon is seen by the textbook Vontade de saber português (ALVES: BRUGNEROTTO, 2012), more precisely on the volume directed to the students of the sixth grade of public education. To do so, we observe some of the approaches to teach linguistic variation provided by the PCN (BRASIL, 1998) and PNLD (BRASIL, 2014) putting them in parallel with the treatment of the linguistic variation on the referred textbook. Based on the analysis, we noticed that, even though we have progressed significantly when it comes about the elaboration of approaches for the linguistic variation in textbooks and, consequently, in the classroom, it is still possible to find some gaps and even mismatching on the way the linguistic variation is seen by such materials. This way, we comprehend that the approach of one of the most important mechanisms of natural language has been compromised.

KEYwoRDS: Proposals; Linguistic Variation; Textbook. 


\section{Introdução}

o longo, principalmente, das três últimas décadas, é notável o aumento das preocupações em torno do trabalho com a variação linguística em sala de aula. Parte desse crescimento pode ser atribuída a dois fatores. Primeiro, o reconhecimento das línguas naturais ${ }^{1}$ como fenômenos heterogêneos e passíveis de observação sistemática, conforme defende a Sociolinguística (LABOV, 2001, 2008), abriu novos e amplos leques de possibilidades para a observação do fenômeno linguístico. Assim, as pesquisas sociolinguísticas desenvolvidas no Brasil, há pouco mais de cinco décadas, vêm mostrando que nossa língua é constituída por conjuntos de variedades que mantêm relações significativamente estreitas com os aspectos socioculturais dos falantes, bem como das comunidades de fala ${ }^{2}$ das quais fazem parte.

Em segundo lugar, vemos que o público que frequenta nossas escolas tornou-se mais heterogêneo em função, ao menos em parte, dos movimentos migratórios de indivíduos, antes residentes em zonas rurais, para zonas urbanas (BORTONI-RICARDO, 2004). Esse fato tem exigido das instituições de ensino formal posturas mais abertas e atentas para o trato das muitas realidades sociolinguísticas com as quais os jovens estudantes chegam as nossas, comumente lotadas, salas de aula.

De igual modo, também são notórias as tentativas, por parte dos órgãos educacionais, em promover os avanços das descobertas científicas no cenário pedagógico e também em atender às demandas socioculturais de

${ }_{1}^{1}$ Por línguas naturais entendemos os sistemas linguísticos adquiridos pelos falantes de forma espontânea ao longo de suas vidas e com base nas relações estabelecidas dentro de seus respectivos grupos sociais

2 Embora o conceito de comunidade de fala seja de notável complexidade, entendemos, juntamente com Labov (2008, p. 188), que "uma comunidade de fala não pode ser concebida como um grupo de falantes que usam todos as mesmas formas; ela é mais bem definida como um grupo que compartilha as mesmas normas a respeito da língua [...]. Os membros de uma comunidade de fala compartilham um conjunto comum de padrões normativos, mesmo quando encontramos variação altamente estratificada na fala real". "uma clientela diferente daquela que veio frequentando os bancos escolares até a década de 60" (FERREIRA, 2001, p. 02).

Como parte de tais tentativas, foram elaborados em meados das décadas de 1980, 1990 e 2000 documentos oficiais como os Parâmetros Curriculares Nacionais, os PCN de língua portuguesa (BRASIL, 1998) e o Programa Nacional do Livro Didático, o PNLD (BRASIL, 2014). Os primeiros buscam oferecer uma série de propostas didáticas para as disciplinas que compõem o quadro curricular do ensino básico. Já os segundos, figuram como guias através dos quais o Ministério da Educação avalia, compra e distribui materiais didáticos para as disciplinas que constituem o quadro do ensino fundamental ${ }^{3}$.

Assim, muitas das orientações fornecidas pelos referidos materiais encontram respaldo em áreas da Linguística como a já citada Sociolinguística, Linguística Textual, Análise do Discurso, Pragmática, dentre outras. Embora tais vertentes apresentem métodos e objetivos distintos para a observação das línguas naturais, todas nos parecem ter um ponto em comum, isto é, o reconhecimento de que as línguas são, antes de tudo, instrumentos de interação social e, portanto, heterogêneas.

A partir de um longo, lento e apurado trabalho, as propostas dos PCN (BRASIL, 1998) foram incorporadas aos livros didáticos, visto que eles "são ferramentas ou instrumentos que a maioria dos professores das escolas públicas brasileiras utiliza em sala de aula" (MORAIS, 2015, p. 191). Nesse sentido, muitos trabalhos têm sido desenvolvidos com o intuito de observar como os materiais didáticos estão incorporando as propostas para o trabalho com a variação linguística (BORTONI-RICARDO; ROCHA, 2014; LIMA, 2014; MORAIS, 2015; MARQUES; BARONAS, 2015; RAZKY; FEITERO, 2015).

${ }^{3}$ O processo de seleção para livros didáticos do ensino médio acontece por meio do Programa Nacional do Livro Didático Para o Ensino Médio (PNLEM), iniciado em 2004, com propostas apenas para as disciplinas de Língua Portuguesa e Matemática. 
Não raro, tais estudos apontam lacunas e até mesmo inadequações quanto ao tratamento da variação linguística em livros didáticos. Disso decorre a necessidade de estarmos constantemente revisitando as propostas dos documentos oficiais. De igual modo, precisamos atentar para os modos através dos quais os materiais didáticos abordam uma das mais importantes propriedades das línguas naturais, isto é, a heterogeneidade linguística.

Diante de tais problemáticas, discutimos, neste artigo, algumas das propostas dos PCN (BRASIL, 1998) e PNLD (BRASIL, 2014) para o tratamento da variação linguística nos eixos diatópico, diafásico e diastrático em sala de aula e, analisamos, no espaço deste texto, como um livro didático direcionado a alunos do ensino fundamental contempla o fenômeno em tela. Para tanto, selecionamos o volume recomendado para alunos dos $6^{\circ}$ ano que compõe a coletânea Vontade de saber português (ALVES; BRUGNEROTTO, 2012) aprovada pelo Ministério da Educação para os anos de 2014, 2015 e 2016 e distribuída gratuitamente para alunos dos anos finais do ensino fundamental da rede pública.

A escolha dessa coletânea se deu a partir do nosso contato e, consequentemente, trabalho com ela durante nossas experiências enquanto docentes. Salientamos que, em virtude da complexidade que envolve o tratamento da variação linguística em materiais didáticos, o que talvez nos impeça de, dentro do espaço do qual dispomos, abordar detidamente tais problemáticas também nos demais volumes da série Vontade de saber português, optamos por analisar apenas o primeiro volume da coletânea.

Por questões metodológicas, dividimos este artigo em duas seções além desta introdução e das considerações. Assim, na seção um, esboçamos alguns comentários acerca das principais propostas para o trabalho com a variação linguística fornecidas pelos PCN (BRASIL, 1998) e PNLD (BRASIL, 2014). Já na seção dois, analisamos o tratamento dado ao fenômeno de variação em livro didático, até aqui, não analisado. Frisamos que, conforme analisamos o material selecionado, apresentamos algumas propostas, ainda que discretas, para o trabalho com a variação em sala de aula.

\section{0 que dizem os documentos oficiais}

Conforme mencionamos nos parágrafos anteriores, desde que foram iniciados, em meados da década de 1960, os estudos desenvolvidos à luz dos pressupostos-teórico metodológicos da sociolinguística, em suas muitas vertentes, indicam que as línguas naturais são fenômenos heterogêneos e mantêm relações significativamente estreitas com as sociedades das quais fazem parte (CAMACHO, 2013). Esse reconhecimento percorreu um longo caminho até ser incorporado aos documentos oficiais que buscam orientar o trabalho formal com a língua materna. Contudo, hoje é possível encontrar menção direta à heterogeneidade linguística nos PCN (BRASIL, 1998) de língua portuguesa, para os quais:

A língua portuguesa, no Brasil, possui muitas variedades dialetais Identificam-se geográfica e socialmente as pessoas pela forma como falam. Mas há muitos preconceitos decorrentes do valor social relativo que é atribuído aos diferentes modos de falar: é muito comum se considerarem as variedades linguísticas de menor prestígio como inferiores ou erradas (p. 26, grifos nossos).

Com isso, vemos que, mesmo em face do reconhecimento de que a heterogeneidade linguística é uma das principais propriedades das línguas naturais, mais especificamente do português do Brasil, nem sempre as diferenças linguísticas são percebidas de forma positiva. Acontece que sobre as chamadas variantes linguísticas - formas alternativas de se dizer a mesma coisa do ponto de vista referencial (LABOV, 2008) - são lançados valores positivos ou negativos. 
Tais valores, por sua vez, não são atribuídos por razões intrínsecas às nossas variantes, visto que não há, do ponto de vista linguístico, nenhuma forma superior ou inferior à outra. Na verdade, o acarretamento de valores às formas variantes dá-se sempre por meio de uma teia extremamente complexa de relações sociais nas quais se evidenciam tensões de poder refletidas nas línguas, pois, como bem nos diz Gnerre (1985, p. 4, aspas no original) “uma variedade linguística 'vale' o que 'valem' na sociedade os seus falantes, isto é, como reflexo do poder e da autoridade que eles têm nas relações econômicas e sociais".

Um dos fenômenos que emerge dessas problemáticas e muito preocupa os sociolinguistas é o chamado preconceito linguístico, manifestado, pelo menos a princípio, através de comentários jocosos sobre a fala e/ou escrita do próximo, ou até mesmo sobre nossa própria fala ou escrita (BAGNO, 2009). A esse respeito, frisamos que uma das recomendações dos PCN (BRASIL, 1998) é de que "o problema do preconceito linguístico disseminado na escola em relação às falas dialetais deve ser enfrentado, na escola, como parte do objetivo educacional mais amplo de educação para o respeito à diferença" (BRASIL, 1998, p. 26). Neste sentido, o trabalho com a variação linguística em sala de aula torna-se tarefa imprescindível.

Assim, é notória a preocupação dos PCN (BRASIL, 1998) de língua portuguesa com a heterogeneidade linguística, afirmando que o trabalho com a variação deve fazer parte do quadro de atividades desenvolvidas em sala de aula. Acreditamos que esse espaço, em função da heterogeneidade do público que vem recebendo, pode ser tido como privilegiado para tentar combater o chamado fenômeno do preconceito linguístico. Diante disso, os documentos oficiais propõem que a variação linguística deve ser contemplada em seus eixos diatópico, diastrático e diafásico.

De acordo com Alkmim (2012), o termo variação diatópica ou geográfica compreende o conjunto de variedades identificável na fala de sujeitos pertencentes a diferentes regiões geográficas. Assim, é possível encontrar no plano lexical, fonético- fonológico, morfossintático etc., diferenças quanto ao uso da língua. No plano lexical, por exemplo, é sabido que falantes oriundos de alguns pontos do Nordeste usam o termo macaxeira para designar um determinado alimento, enquanto que falantes da região sudeste tendem a usar o termo aipim para referir o mesmo alimento (COELHO et al., 2012).

A variação diastrática ou social, por sua vez, compreende diferenças linguísticas resultantes de estratificações na identidade social dos falantes como, por exemplo, o sexo, a classe social, idade, dentre outros. A esse respeito, Camacho (1978) chama a atenção para o fato de que o uso do diminutivo como em bonitinho, gostosinho, vermelhinho, danadinho é mais frequente no comportamento linguístico de indivíduos do sexo feminino do que masculino.

Além disso, é sabido que os falantes tendem a (e devem) procurar ajustar seus comportamentos linguísticos em função do contexto de interação, da identidade social dos seus interlocutores, bem como dos seus e dos interesses de seus ouvintes etc. Os fenômenos de variação relacionados a esses elementos são, portanto, chamados de variação diafásica, estilística ou ainda de registros (LABOV, 1966; BELL, 1984). Embora tenhamos sinalizado esses três eixos separadamente, é importante lembrar que as fronteiras entre eles nem sempre são claras, pois "onde termina uma e onde começa a outra e qual a prevalência de uma sobre a outra" (ARAGÃO, 2010, p. 37) são questões que preocupam os estudiosos desde o início das observações sobre tais fenômenos.

Em consonância com as indicações fornecidas pelos PCN (BRASIL, 1998), o PNLD (BRASIL, 2014) destaca que nos livros didáticos de língua portuguesa é preciso "considerar e respeitar as variedades regionais e sociais da língua, promovendo o estudo das normas urbanas de prestígio nesse contexto sociolinguístico" (p. 19, destaques nossos). Posto isso, convém atentar, 
juntamente com outros estudiosos (CYRANKA, 2014; MARTINS; VIEIRA; TAVARES, 2014), para algumas contradições dentro de tais proposições.

Afinal, a partir da citação anterior, é possível perceber que se, por um lado, os referidos documentos defendem o trabalho com a diversidade linguística em suas muitas faces e tentam promover a conscientização dos estudantes de que não há, do ponto de vista linguístico, variantes superiores ou inferiores nos diferentes modos de falar, por outro, é notável a ênfase sobre as chamadas normas urbanas de prestígios ${ }^{4}$ pincipalmente na modalidade escrita. A esse respeito, Coelho et al. (2015, p. 138, destaques nossos) indicam que "a norma culta deve ter lugar garantido na escola, mas não deve ser a única (norma) privilegiada no processo de conhecimento linguístico proporcionado ao aluno".

Mesmo em face desse paradoxo, o PNLD (BRASIL, 2014), juntamente com os PCN (BRASIL, 1998), prossegue indicando a necessidade de reconhecer e acolher as realidades sociolinguísticas com as quais o alunado se insere no contexto de educação formal, visto que os conhecimentos linguísticos adquiridos, antes de entrar na escola, são plenos e atendem perfeitamente as demandas de sua participação em "seus convívios sociais prévios" (BRASIL, 2014, p. 19). Seria, portanto, tarefa da escola não tentar substituir os conhecimentos linguísticos dos alunos, mas sim, trabalhar no sentido de ampliá-los, contribuindo mais plenamente para o desenvolvimento de sua educação sociolinguística e, consequentemente, para a formação da cidadania dos estudantes. Isso pode ser constatado na seguinte passagem:

Considerando os diferentes níveis de conhecimento prévio, cabe à escola, promover a sua ampliação de forma que, progressivamente, durante os oito anos do ensino fundamental, cada aluno se torne capaz de interpretar diferentes textos que circulam socialmente, de assumir a palavra e, como cidadão, de produzir textos eficazes nas mais variadas situações (BRASIL, 1998 , p. 21, grifos nossos)

4 Termo usado nos documentos oficiais para substituir o termo 'norma culta'.
Visando, portanto, não ferir as realidades sociolinguísticas dos discentes, mas sim ampliar seus conhecimentos, os PCN (BRASIL, 1998) destacam que, para o trabalho com a diversidade linguística nos planos diatópico, diastrático e diafásico, em particular para com esse último, durante as aulas da disciplina de língua portuguesa, deve ser levado em consideração o fato de que:

A questão não é falar certo ou errado, mas saber qual forma de fala utilizar, considerando as características do contexto de comunicação, ou seja, saber adequar o registro às diferentes situações comunicativas. É saber coordenar satisfatoriamente o que falar e como fazê-lo, considerando a quem e por que se diz determinada coisa. É saber, portanto, quais variedades e registros da língua oral são pertinentes em função da intenção comunicativa, do contexto e dos interlocutores a quem o texto se dirige. A questão não é adequação da forma, mas de sua adequação às circunstâncias de uso, ou seja, de utilização eficaz da linguagem: falar bem é falar adequadamente, é produzir o efeito pretendido (BRASIL, 1998, p. 26, grifos nossos).

Desse modo, é essencial que as atividades desenvolvidas na disciplina de língua materna foquem "a língua portuguesa tal como se fala e se escreve fora da escola, a língua que se fala em instâncias públicas e a que existe nos textos escritos que circulam socialmente" (BRASIL, 1998, p. 25). Como um dos meios para alcançar tais objetivos, defende-se a priorização do trabalho em sala de aula com a produção de um número cada vez maior de gêneros textuais tanto orais como escritos, desde os mais formais aos menos formais. A ênfase, contudo, novamente é atribuída aos primeiros, visto que, para os nossos PCN, "a aprendizagem de procedimentos eficazes tanto de fala como de escuta, em contextos mais formais, dificilmente ocorrerá se a escola não tomar para si a tarefa de promovê-la" (BRASIL, 1998, p. 27).

Em consonância com tais propostas, o guia fornecido pelo PNLD (BRASIL, 2014) recomenda que, durante a escolha dos livros didáticos que norteiam os trabalhos dos professores em sala de aula, deve-se observar se tais materiais, no que tange ao conjunto de textos fornecidos são: 
[...] representativos da heterogeneidade própria da cultura e da escrita inclusive no que diz respeito à autoria, a registros, estilos e variedades (sociais e regionais) linguísticas do Português -, permitindo ao aluno a percepção de semelhanças e diferenças entre tipos de textos e gêneros diversos pertencentes a esferas socialmente mais significativas de uso da linguagem (BRASIL, 2014, p. 17, grifos no original).

Com essas e outras propostas, é esperado que, ao término desse período, nossos estudantes sejam capazes de "conhecer e respeitar as diferentes variedades linguísticas do português falado" (BRASIL, 1998, p. 33), bem como de poder "conhecer e analisar criticamente os usos da língua como veículo de valores e preconceitos de classe, credo, gênero ou etnia" (op. cit.). Essas e outras propostas têm, portanto, norteado o trabalho de muitos professores de língua em sala de aula, assim como a elaboração de materiais didáticos. E, embora muito já tenha sido dito a respeito da variação linguística nos materiais didáticos direcionados ao ensino formal de língua portuguesa, apresentamos, na seção seguinte, uma análise do tratamento dado pela coletânea Vontade de saber português, até aqui, não analisada, à variação linguística.

\section{Variação linguística em livro didático}

O livro analisado neste artigo corresponde ao primeiro volume da coletânea Vontade de saber português (ALVES; BRUGNEROTTO, 2012), avaliada e aprovada pelo PNLD (BRASIL, 2014) no ano de 2014 como uma das coletâneas direcionadas as séries finais do ensino fundamental para os anos de 2014, 2015 e 2016 na rede pública de ensino. O material foi lançado pela editora FTD e pode ser encontrado nos manuais do PNLD (BRASIL, 2014) através do código (27494COLO1). Além do volume para os alunos do $6^{\circ}$ o ano, a coletânea possui ainda mais três volumes para o 7으, $8^{\circ}$ e e $9^{\circ}$ ano.
O volume para o 6o ano está dividido em seis grandes capítulos e, logo no primeiro, as autoras iniciam o trabalho direto com a variação linguística com uma tirinha da turma do Xaxado, do cartunista baiano Antônio Luiz Ramos Cedraz, vejamos:

Figura 1 - Tirinha da Turma do Xaxado

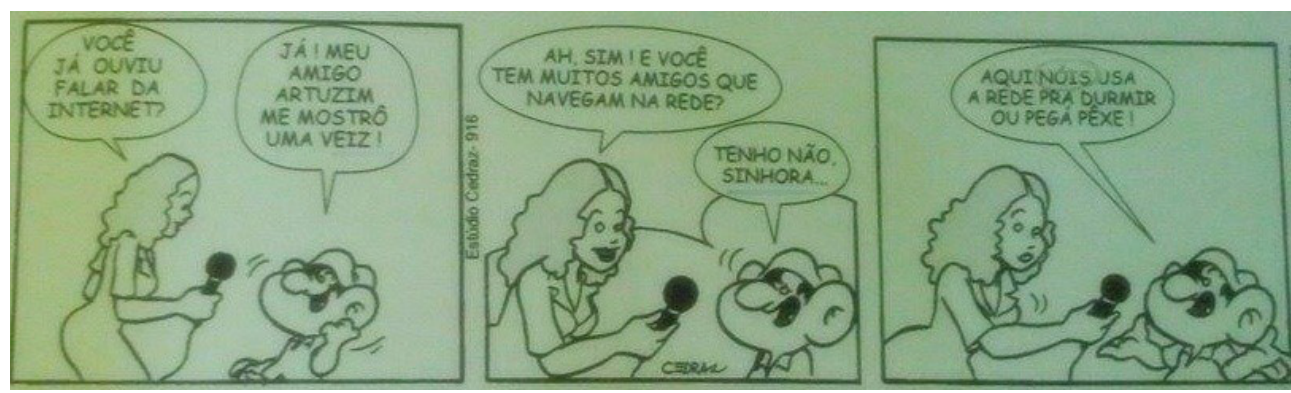

Fonte: Extraído de Alves e Brugnerotto (2012, p. 27)

A partir da tirinha, as autoras chamam atenção para o fato de que, embora falem a mesma língua, é possível perceber que Zé Pequeno - personagem de origem rural descrito nas tirinhas de Cedraz como um garoto preguiçoso que foge constantemente da escola - e a jornalista apresentam distinções quanto ao português que falam (ALVES; BRUGNEROTTO, 2012). De igual modo, as autoras destacam que:

A repórter emprega as normas urbanas de prestígio. Essas formas são utilizadas em livros, jornais, telejornais, revistas, correspondências a autoridades etc., ou seja, empregada em situações formais de comunicação. Zé pequeno usa uma forma de falar empregada principalmente no dia a dia, em situações informais e com pessoas com quem se tem mais intimidade (ALVES; BRUGNEROTTO, 2012, p. 27, destaques nossos).

Dentre os aspectos que poderiam, mas não foram mencionados pelas autoras, destacamos as diferentes maneiras que marcam a compreensão 
por parte dos personagens, do termo 'rede', o qual recebe concepções distintas, segundo o contexto sócio-histórico do qual fazem parte a repórter e Zé Pequeno. Até mesmo porque são justamente as diferenças quanto à denotação do termo 'rede' que geram o humor da tirinha.

Neste sentido, defendemos a importância de levar o alunado a refletir sobre os aspectos sócio-históricos dos falantes. No caso dos personagens da tirinha, temos o fato evidente de que um é oriundo dos grandes centros urbanos, e o outro, da zona rural. Contudo, as explicações das autoras ficam limitadas, no que tange à variação linguística, ao fato de que um faz uso de formas prestigiadas, as quais devem ser usadas em situações formais de interação e com sujeitos com os quais não temos muita intimidade, enquanto que o outro usa formas próximas ao falar do dia a dia.

Acreditamos que esse tipo de abordagem pode gerar confusão quanto à compreensão dos alunos. Afinal, supomos que Zé Pequeno e a repórter nunca conversaram antes da entrevista, o que poderia levar o primeiro - conforme as explicações dadas pelas autoras - a optar por variantes prestigiadas. Além disso, os dois estão inseridos na mesma situação de interação, isto é, uma entrevista, o que novamente poderia pressionar o garoto a usar variantes prestigiadas. De forma simplificada, acreditamos que o que está em jogo não é a diferenciação das formas segundo o grau de formalidade ou informalidade da situação, mas, sim, aspectos próprios dos contextos sócio-históricos dos personagens presentes em suas falas.

Em conformidade com o que apontamos, logo em seguida, as autoras ressaltam a relevância de conhecer os conjuntos de variedades que compõem o português brasileiro, fruto, por exemplo, de divergências entre os fatores que assinalam as identidades sociais dos falantes, como o sexo, grau de escolaridade, a faixa etária, o status socioeconômico etc. Além disso, há diferenças quanto ao tipo de situação de interação e distâncias geográficas, que podem, de forma conjunta, atuar sobre os comportamentos linguísticos dos brasileiros.

Contudo, as autoras não associam de forma direta e clara os referidos fatores ao contexto da tirinha. De igual modo, não localizamos, nesse primeiro momento, atividades de reflexão a serem trabalhadas com os discentes sobre os aspectos de variação linguística presentes na tirinha. Evidentemente, sabemos que os professores podem mediar às associações entre as explicações fornecidas pelo livro didático aos exemplos dados por ele, contudo, julgamos importante que o material faça isso de modo claro nos primeiros momentos de atividades sobre variação linguística com os alunos.

Por último, as autoras enfatizam que o uso das formas variantes é influenciado por fatores como sexo, escolaridade etc., "mostram que não há uma forma correta e outra incorreta de falar. No entanto, é importante ressaltar a necessidade da utilização das normas urbanas de prestígio em registros formais de comunicação" (ALVES; BRUGNEROTTO, 2012, p. 27, grifos nossos). Conforme ressaltamos na citação, em meio à ênfase dada ao uso da chamada norma urbana de prestígio - seguindo, assim, as orientações dos PCN (BRASIL, 1998) e PNLD (BRASIL, 2014) referidas na seção anterior - as autoras atentam, ainda que muito discretamente, para o fato de que, na língua não há formas corretas ou incorretas. Isso pode ser tido como uma forma de introduzir o trabalho sobre a compreensão do fenômeno do preconceito linguístico. Contudo, questões em torno desse fenômeno não tornam a ser mencionadas pelas autoras ao longo do primeiro volume da série Vontade de saber português.

Posto isso, destacamos que, em um segundo momento, as autoras apresentam um trecho do poema Catulo da Paixão Cearense, de Braz Macacão. Vejamos: 
Figura 2 - Fragmento do poema "Catulo da Paixão Cearense" de Braz Macacão

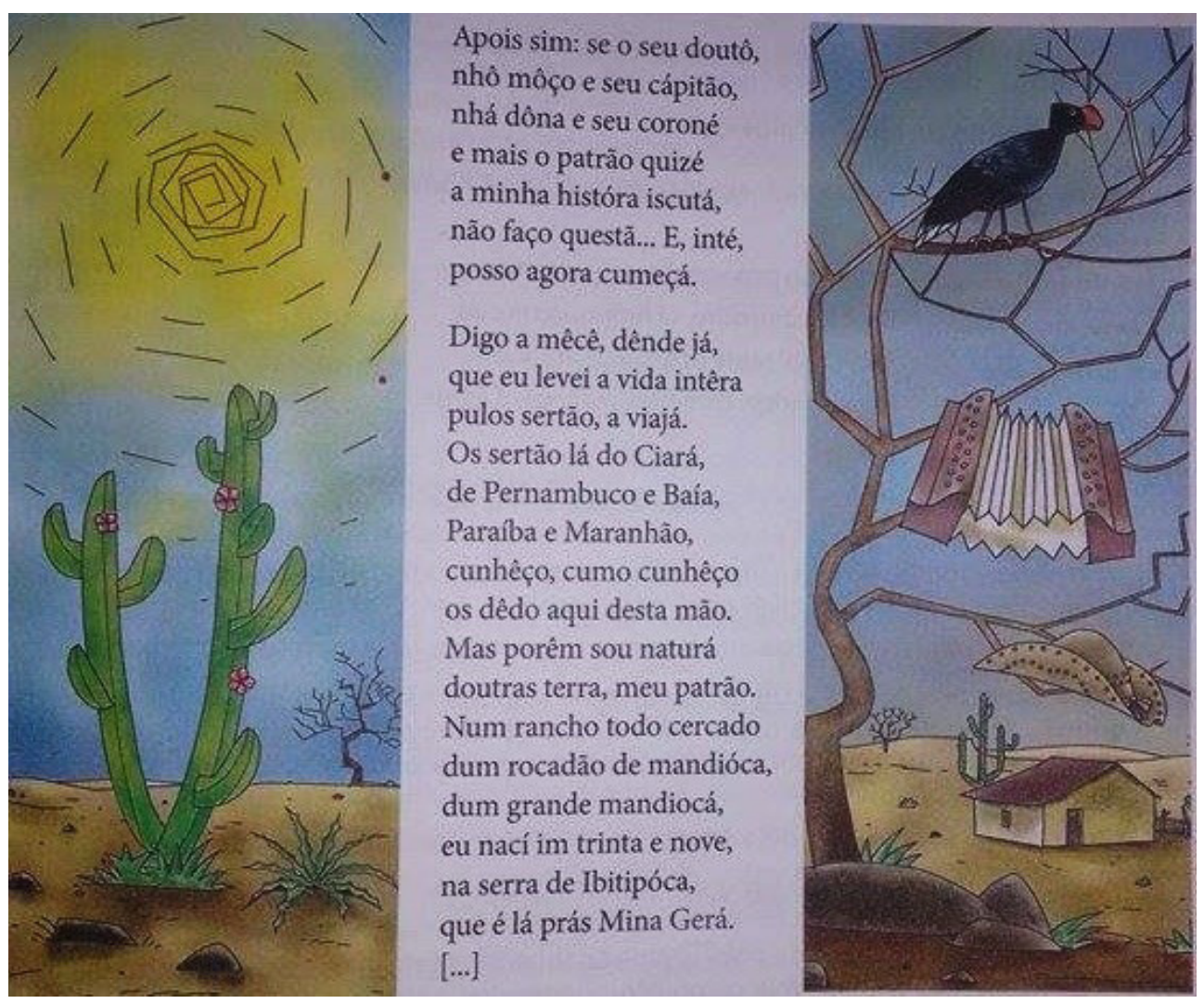

Fonte: Alves e Brugnerotto (2012, p. 29).

Ao observarmos os exercícios de reflexão sobre o referido poema, propostos pelas autoras, percebemos que, ao lado do destaque para aspectos que marcam o gênero poema, como a rima, a estrofe, versos etc., elas propõem que os alunos identifiquem e reflitam sobre a presença de termos como doutô, nhô, moço, dentre outros presentes nos versos do poema. Assim, o foco para o trato da variação centra-se essencialmente no nível lexical.
Diante disso, convém destacar as preocupações de Bagno (2010) com esse tipo de abordagem, visto que esses são fenômenos que "poderíamos chamar de superficiais" (p. 132).

Naturalmente, Bagno (2010) reconhece a relevância de abordar fenômenos de variação linguística situados no espaço lexical e fonéticofonológico, afinal "o preconceito linguístico entra em ação imediatamente quando alguém abre a boca para falar e exibe pronúncias e palavras características de uma região ou classe social desprestigiada" (BAGNO, 2010, p. 132). Bagno (op. cit.) reconhece também a necessidade de nossos materiais enfatizarem "um nível da variação que em geral é pouco abordado: a variação morfossintática, ou seja, os usos diferenciados que cada grupo social faz dos recursos gramaticais da língua" (BAGNO, 2010, p. 132, destaques no original).

Compartilhamos de tais ideias e assinalamos que uma das grandes lacunas que percebemos no volume direcionado aos alunos do $6^{\circ}$ ano da rede pública, elaborado por Alves e Brugnerotto (2014) é, justamente, o trabalho com a variação diastrática. Pois, embora as autoras mencionem, como já destacamos nos parágrafos anteriores, que fatores como o sexo, a faixa etária, escolaridade, o status socio-econômico, isto é, ligados à identidade social dos falantes, podem influenciar e diferenciar os comportamentos linguístico dos brasileiros, não apresentam, ao longo do livro, exemplos ou atividades que permitam aos alunos observarem fenômenos relacionados a esses fatores.

Além disso, não localizamos, ao longo de toda a obra, um único exemplo de variação morfossintática de cunho estigmatizado como, por exemplo, a famigerada ausência de concordância verbal, o que certamente abriria espaço para o trabalho, de modo mais preciso, com o fenômeno do preconceito linguístico. Isso também possibilitaria a observação quanto à presença de formas diferentes no quadro do sistema pronominal. Tais formas têm acarretado mudanças nos parâmetros de concordância verbal. Essas mudanças, por sua vez, têm resultado também na classificação das 
variedades em estigmatizadas, prestigiadas ${ }^{5}$ e na norma padrão, conforme o modelo sugerido por Bagno (2010):

Quadro 1 - Concordância verbal em diferentes variedades

\begin{tabular}{|l|l|l|}
\hline $\begin{array}{l}\text { Variedades mais } \\
\text { estigmatizadas }\end{array}$ & Variedades mais prestigiadas & Norma padrão \\
\hline Eu falo & Eu falo & Eu falo \\
Você (Tu) fala & Você fala & Tu falas \\
A gente (nós) fala & Ele fala & Ele fala \\
Eles fala & A gente fala & Nós falamos \\
& Nós falamos & Vós falais \\
& Vocês falam & Eles falam \\
& Eles falam & \\
\hline
\end{tabular}

Fonte: Adaptado de Bagno (2010, p. 133)

Posto isso, convém mencionar que as autoras recorrem, com notável frequência, a textos que apresentam aspectos de gêneros como cartas, conversas telefônicas, páginas de diários e tentam, novamente, enfatizar apenas aspectos lexicais como gírias e, assim caracterizar a linguagem de falantes mais jovens em oposição a falantes mais velhos. A esse respeito, destacamos, na Figura 3 adiante, um dos textos usados pelas autoras para tratar de tais questões.

No que tange ao tratamento da variação diafásica que, conforme já mencionamos, envolve os diferentes tipos de registros, indo dos mais formais aos menos formais, por exemplo, bem como as identidades e propósitos dos locutores e interlocutores, é notável o grande número de textos que trabalham aspectos de gêneros textuais como a conversa telefônica, cartas, ao lado das cartas comerciais, gêneros literários, como o romance, conto

5 Termos usados para substituir norma popular e norma culta. etc., usados para tentar fazer o aluno perceber as diferenças linguísticas e os aspectos peculiares presentes em cada um deles. Diante disso e, em consonância com o que já discutimos, percebemos que, ao trabalhar com fenômenos de variação linguística, Alves e Brugnerotto (2012) focam, principalmente, a variação diafásica.

Figura 3 - Fragmento de diário pessoal

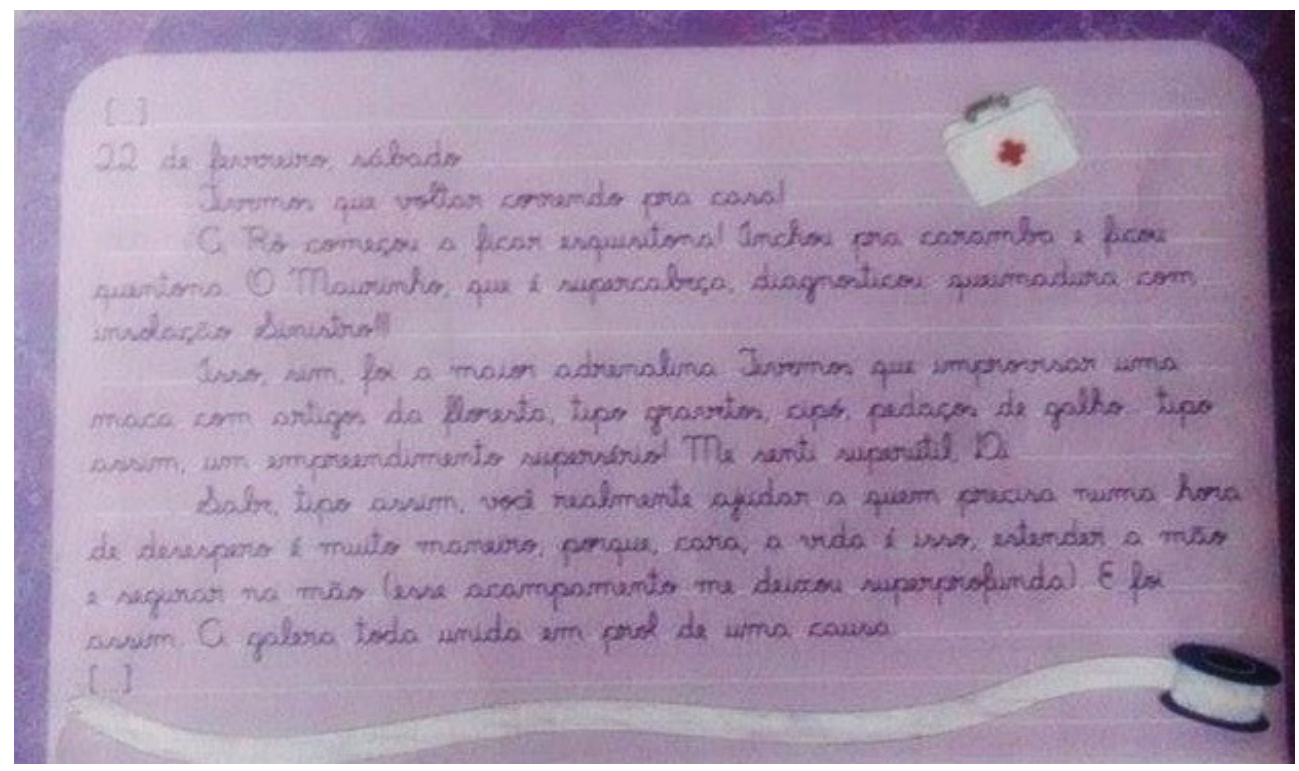

Fonte: Alves e Brugnerotto (2012, p. 28)

Naturalmente, esse tipo de abordagem é de suma importância para o trabalho com a variação linguística nas aulas de língua materna. Afinal, é preciso mostrar àquele que fala e/ou escreve a necessidade de estar sempre adaptando, moldando seus comportamentos linguísticos às mais diferentes situações de interação e, com isso, buscar perceber "a verdadeira natureza 
da língua: heterogênea e plural" (MORAIS, 2015, p. 189). Não obstante, é preciso não esquecer também que os fenômenos de variação precisam ser focados e trabalhados nos eixos diatópico, diastrático e diafásico (BORTONI-RICARDO, 2004, 2005) e não apenas, ou principalmente no primeiro e último.

Infelizmente, ao analisarmos o primeiro volume da coletânea de livros direcionada aos alunos dos anos finais do ensino fundamental da rede pública, elaborada por Alves e Brugnerotto (2012), percebemos que considerações acerca da variação diastrática estão quase que ausentes e, quando aparecem, é de maneira superficial.

Diante disso, é notório que o material analisado apresenta lacunas quanto ao tratamento da variação linguística. Aliás, o trabalho com esses fenômenos dentro na coletânea de Alves e Brugnerotto (2012) já era apontado pelo PNLD (BRASIL, 2014) como "superficial e reduzida" (BRASIL, 2014, p. 116). Mesmo assim, a coletânea foi aprovada, comprada, distribuída e deve ser usada, ao menos, até o fim de 2016, por professores e alunos dos anos finais do ensino fundamental.

Isso nos leva a crer que, apesar de muito já ter sido feito, ao menos na teoria, com o intuito de melhorar o trabalho com a variação em sala de aula, na prática, nossos materiais didáticos que tendem a nortear o trabalho com a língua materna em sala de aula carecem de mais rigor e atenção ao abordar a variação linguística nos eixos diatópico, diafásico e diastrático.

\section{Considerações finais}

Ao longo deste artigo, vimos que tanto os PCN (BRASIL, 1998) como o PNLD (BRASIL, 2014), documentos que visam nortear o trabalho com o ensino formal de língua portuguesa no Brasil, mostram-se empenhados em trazer para dentro de nossas salas de aula os avanços da ciência da linguagem, em particular da Sociolinguística. Assim, privilegiam o trabalho com os fenômenos de variação linguística como parte dos objetivos para formação escolar e da cidadania dos jovens brasileiros.

De igual modo, constatamos, através das análises realizadas aqui, que o material didático, de modo mais específico, o volume direcionado ao $6^{\circ}$ ano do ensino fundamental que compõe a coletânea Vontade de saber português (ALVES; BRUGNEROTTO, 2012) busca levar para dentro das salas de aula questões que envolvem a variação linguística. Contudo, também são notáveis algumas lacunas presentes no tratamento dado pelo referido material didático a heterogeneidade linguística.

\section{Referências}

ALKMIM, T. M. Sociolinguística (Parte I). In: MUSSALIN, F.; BENTES A. C. (Org.). Introdução à linguística: domínios e fronteiras. 9. ed. São Paulo: Cortez, 2012.

ALVES, R.; BRUGNEROTTO, T. Vontade de saber português, 6o ano. São Paulo: FTD, 2012.

ARAGÃO. M. do S. Variantes diatópicas e diastráticas na língua portuguesa do Brasil. Graphos, João Pessoa, v. 12, n. 2, p. 35-51, 2010.

BAGNO, M. Nada na língua é por acaso: por uma pedagogia da variação linguística. 3. ed. São Paulo: Parábola Editorial, 2009.

BELL, A. Language style as audience design. Language in Society, v. 13, n. 2, p. 145-201, 1984. https://doi.org/10.1017/S004740450001037X

BORTONI-RICARDO, S. M. Educação em Língua materna: a sociolinguística na sala de aula. São Paulo: Parábola Editorial, 2004.

Nós cheguemu na escola, e agora? Sociolinguística na sala de aula. São Paulo: Parábola Editorial, 2005.

BORTONI-RICARDO, S. M.; ROCHA, M. do R. O ensino de português e a variação linguística em sala de aula. In: MARTINS, M. A.; VIEIRA, S. R.; TAVARES, M. A. (Org.). Ensino de português e sociolinguística. São Paulo: Contexto, 2014. p. 37-55. 
BRASIL, Ministério da Educação e do Desenvolvimento; Secretaria de Educação Fundamental. Parâmetros Curriculares Nacionais: Língua Portuguesa. Brasília-DF: MEC/ SEF, 1998.

Secretaria de Educação Fundamental. Programa Nacional do Livro Didático de Língua Portuguesa. Brasília-DF: MEC/SEF, 2014.

CAMACHO, R. G. A variação linguística. In: Subsídios à proposta curricular de língua portuguesa para o segundo grau. São Paulo: CENP, Secretaria do Estado da Educação, 1978. Vol. 4. p. 29-34.

Da linguística formal à linguística social. São Paulo: Parábola Editorial, 2013.

COELHO, I. L.; GÖRSKI, E. M.; SOUZA, C. M. N. de; MAY, G. H. Para conhecer sociolinguística. São Paulo: Contexto, 2015. (Coleção para conhecer linguística).

CYRANKA, L. Avaliação das variantes: atitudes e crenças em sala de aula. In: MARTINS, M. A.; VIEIRA, S. R.; TAVARES, M. A. (Org.). Ensino de português e sociolinguística. São Paulo: Contexto, 2014. p. 133-155.

FERREIRA, N. S. de A. Ainda uma leitura dos Parâmetros Curriculares Nacionais de Língua Portuguesa. Revista do Instituto Brasileiro de Edições Pedagógicas, v. 2, p. 20-27, 2001.

GNERRE, M. Linguagem, escrita e poder. São Paulo: Martins Fonte, 1985

GUY, G. R.; ZILLES, A. M. S. O ensino de língua materna: uma perspectiva sociolinguística. Calidoscópio, v. 4, n. 52, p. 39-50, 2006.

LABOV, W. The social stratification of English in New York City. Washington, DC: Center for Applied Linguistics, 1966.

. Principles of Linguistic Change - Social Factors. Oxford: Blackwell, 2001.

Padrões Sociolinguísticos. Tradução de Marcos Bagno, Maria Marta Pereira Scherre, Caroline Rodrigues Cardoso. São Paulo: Parábola Editorial, 2008.

LIMA, R. J. Variação linguística e os livros didáticos de português. In: MARTINS, M. A.; VIEIRA, S. R.; TAVARES, M. A. (Org.). Ensino de português e sociolinguística. São Paulo: Contexto, 2014. p. 115-131.

MARQUES, T. M.; BARONAS, J. E. de A. Pedagogia da Variação Linguística: por uma abordagem heterogênea da língua a fim de minimizar o preconceito linguístico. Signum, v. 18, n. 1, p. 283-308, 2015. https://doi.org/10.5433/2237-4876. 2015v18n1p283
MARTINS, M. A.; VIEIRA, S. R.; TAVARES, M. A. Contribuições da sociolinguística brasileira para o ensino de português. In: MARTINS, M. A.; VIEIRA, S. R.; TAVARES, M. A. (Org.) Ensino de português e sociolinguística. São Paulo: Contexto, 2014. p. 9-35.

MORAIS, C. G. O tratamento da diversidade e variação linguística em livros didáticos de português. Letras e Letras, Uberlândia, v. 31, n. 2, p. 188-210, 2015.

RAZKY, A.; FEITEIRO, S. R. Sociolinguística e Livro Didático: uma análise exploratória Signum, Londrina, v. 18, n. 1, p. 309-332, 2015. https://doi.org/10.5433/22374876.2015v18n1p309

Recebido em 19/09/2016. Aceito em 09/03/2017. 